\title{
Avaliação da qualidade das águas subterrâneas em poços do estado do Ceará, Brasil
}

\section{Evaluation of quality of groundwater in wells of Ceará state, Brazil}

\author{
Cecília Leite Costa ${ }^{1}$, Renata Felix de Lima², Germana Costa Paixão³, Lydia \\ Dayanne Maia Pantoja ${ }^{4}$
}

\begin{abstract}
Resumo
A água subterrânea, uma das fontes mais utilizada no Mundo para o consumo humano, tem potencial capacidade de transmissão de doenças causadas por microrganismos patogênicos provenientes de fezes de humanos e animais, ou por meio de substâncias químicas em concentrações fora dos padrões permitidos pela Portaria 2914/2011/MS, por isso tornando-se indispensável a verificação e o acompanhamento de sua potabilidade. O objetivo deste trabalho foi avaliar a qualidade microbiológica e química das águas para consumo humano provenientes de poços e correlacioná-la com o nível de esgotamento sanitário de diversas localidades do Estado do Ceará. No período de janeiro de 2008 a dezembro de 2010, foram coletadas 230 amostras de poços amazonas e tubulares profundos provenientes das cinco macrorregiões do Estado do Ceará, as quais foram submetidas à pesquisa de coliformes totais e Escherichia coli e análises físico-químicas (amônia, nitrito, nitrato e cloretos) nos laboratórios da Companhia de Água e Esgoto do Ceará - CAGECE. Os resultados apontaram elevados níveis de contaminação microbiana nos poços: $40 \%$ das amostras atestaram presença de coliformes totais e $12,2 \%$ de E. coli. Os parâmetros físico-químicos indicaram contaminação por matéria orgânica, em cerca de $10 \%$ das amostras. Medidas preventivas como o aumento do esgotamento sanitário, devem ser realizadas a fim de evitar a transmissão de doenças de veiculação hídrica.
\end{abstract}

Palavras-chave: Poços. Qualidade da água. Esgotamento sanitário. Coliformes totais. Escherichia coli. Parâmetros físico-químicos.

\begin{abstract}
Groundwater, one of the most used fonts in the world for human consumption, has the potential capacity of transmission of diseases caused by pathogenic microorganisms from human and animal feces, or by chemicals in concentrations beyond the standards allowed by Ordinance 2914/2011/MS, making it essential verification and monitoring of its potability. This work aims to evaluate the microbiological and chemical quality for drinking water from wells and correlate it with the sewage level of several places of the State of Ceará. From January 2008 to December 2010 were collected 230 samples of
\end{abstract}

${ }^{1}$ Bióloga graduada pela Universidade Estadual do Ceará. Especialista em Engenharia Ambiental e Saneamento Básico pela Faculdade Integrada do Ceará. Universidade Federal do Ceará, Brasil. Contato principal para correspondência. E-mail: cecilialcosta@, hotmail.com.

${ }^{2}$ Bióloga graduada pela Universidade Federal do Ceará. Mestre em Microbiologia Clínica pela Universidade Estadual do Rio de Janeiro. Companhia de Água e Esgoto do Ceará - CAGECE, Brasil. E-mail: refelix07@hotmail.com.

${ }^{3}$ Médica veterinária pela Universidade Estadual do Ceará. Mestre em Patologia Médica pela Universidade Federal Ceará. Universidade Estadual do Ceará - UECE Brasil. E-mail: germanapaixao2009@hotmail.com.

${ }^{4}$ Resumo da Biografia Bióloga pela Universidade Estadual do Ceará. Mestre em Microbiologia Médica pela Universidade Federal do Ceará. Universidade Estadual do Ceará - UECE, Brasil. E-mail: lydiapantoja@bol.com.br. 
Amazons and deep tubular wells from five geographical regions of the State of Ceará, which were tested for total coliforms and Escherichia coli and physical-chemical analysis (ammonia, nitrite, nitrate and chloride) were made in the laboratories of CAGECE - Ceará Water and Sewerage Company. The results showed high levels of microbial contamination in wells, with $40 \%$ of the samples attested presence of total coliforms and $12.2 \%$ of E. coli. Physical-chemicals parameters indicated contamination by organic matter in about $10 \%$ of the samples. Preventive measures such as increased sewage, should be conducted to prevent the transmission of waterborne diseases.

Keywords: Wells. Water quality. Sewerage. Total coliforms. Escherichia coli. Physical-chemical parameters.

\section{Introdução}

A água é elemento essencial para o desenvolvimento e a manutenção da vida, mas somente 3\% das reservas existentes em nosso planeta são constituídas de água doce. Desse total, apenas $0,3 \%$ pode ser aproveitado para consumo humano, sendo $0,01 \%$ de origem superficial (rios e lagos) e $0,29 \%$ subterrâneas. Os mananciais restantes são constituídos por geleiras, vapor de água e lençóis existentes em grandes profundidades, o que torna inviável economicamente seu aproveitamento para o consumo das populações (BRASIL, 2007).

A maior parte da reserva de água doce em nosso planeta não é encontrada em forma potável. As águas subterrâneas, na maioria das vezes provenientes de poços, geralmente são menos contaminadas por fatores biológicos e químicos do que os mananciais superficiais, pois não ficam expostas aos diversos agentes poluentes (ECKHARDT et al., 2008). Porém, a diversificada utilização das águas subterrâneas é crescente e, com isso, aumenta a importância da qualidade dessas águas. Ademais, fatores como os esgotos domésticos e industriais e fertilizantes utilizados na agricultura, podem comprometer a qualidade dessas águas, tornando-as impróprias para consumo humano (SILVA; ARAÚJO, 2003).

As águas poluídas podem ser fontes de transmissão de diversas doenças, causadas por organismos patogênicos provenientes de fezes de humanos e animais (BRASIL, 2007). Por isso indicadores microbiológicos têm sido utilizados para verificar a existência de poluição fecal, sendo a bactéria Escherichia coli o microrganismo indicador de contaminação fecal mais utilizado no mundo (BARRELL et al., 2002).

Algumas substâncias químicas, como os compostos nitrogenados e os cloretos, também são indicadoras de contaminação por matéria orgânica (BRASIL, 2007).

Portanto, para que a água subterrânea seja considerada potável, é necessária a realização de análises microbiológicas e físico-químicas, a fim de verificar se ela está dentro dos padrões de potabilidade para consumo humano estabelecidos nas normas vigentes no País (CELLIGOI, 1999).

No Brasil, as legislações vigentes que tratam de potabilidade da água para consumo humano e de águas subterrâneas são, respectivamente, a Portaria $\mathrm{n}^{\mathrm{o}}$ 2914, de 12 de dezembro de 2011, do Ministério da Saúde (BRASIL, 2011) e a Resolução no 396, de 3 de abril de 2008, do Conselho Nacional do Meio Ambiente (CONAMA) (BRASIL, 2008).

O Estado do Ceará tem um território de 148.825,6 $\mathrm{km}^{2}$, que equivale a $9,57 \%$ da área total da região Nordeste. É composto por 184 municípios e uma população total de aproximadamente oito milhões de habitantes, dos quais 75\% residem em áreas urbanas (CEARÁ, 2010).

Em 2009, o percentual das áreas urbanas do Estado com abastecimento de água tratada era de $92,14 \%$ e $32,15 \%$ com esgotamento sanitário. $\mathrm{Na}$ área rural, apenas $18,88 \%$ tinham o serviço de abastecimento de água e 0,15\% esgotamento sanitário (CEARÁ, 2010). 
NoEstado do Ceará, o maior índice de esgotamento sanitário é verificado na Região Norte $(41,4 \%)$, seguida pelas Regiões Sul $(36,2 \%)$, Leste $(29,3 \%)$, Oeste (25,9\%) e Central (7,2\%) (COMPANHIA DE ÁGUA E ESGOTO DO CEARÁ, 2011).

O baixo percentual de esgotamento sanitário é preocupante, pois a falta de saneamento representa um risco direto à potabilidade das águas subterrâneas pela infiltração por fossas sépticas e pelo vazamento de redes de esgoto (ZOBY, 2008).

Muitas localidades do Estado do Ceará utilizam poços profundos como fonte de abastecimento, por exemplo, a região Sul do Estado, que possui poços como mananciais em quase metade dos sistemas de abastecimento (SILVA; ARAÚJO; SOUZA, 2007).

Tendo em vista a significativa importância da água subterrânea como fonte de abastecimento e a sua possível contaminação por efluentes domésticos e industriais, principalmente em virtude do pequeno índice de esgotamento sanitário, esta pesquisa avaliou a qualidade da água de poços para consumo humano no Estado do Ceará, por meio de indicadores microbiológicos e físico-químicos.

\section{Metodologia}

As amostras de água foram coletadas de diferentes poços amazonas e tubulares profundos em diversas localidades das cinco macrorregiões do Estado do Ceará entre janeiro de 2008 e dezembro de 2010, perfazendo um total de 230 amostras, como descrito na Tabela 1 .

A maior parte das coletas foi realizada em poços localizados na região Sul do Estado, perfazendo um total de 149 amostras. Isso se deve ao fato de que naquela região quase metade dos sistemas de abastecimento utilizam poços como manancial (SILVA; ARAÚJO; SOUZA, 2007).

Já a região Oeste do Estado teve uma amostragem bem reduzida devido ao fato de que a maioria da população $(84,2 \%)$ utiliza como principal fonte de abastecimento, mananciais superficiais (COMPANHIA DE ÁGUA E ESGOTO DO CEARÁ, 2012).

Tabela 1 - Distribuição geográfica das amostras de água de poços por regiões do Estado do Ceará, Brasil.

\begin{tabular}{llc}
\hline Região & \multicolumn{1}{c}{ Localidades analisadas } & \multicolumn{1}{c}{$\begin{array}{c}\text { Número de amostras } \\
\text { coletadas de água de poço }\end{array}$} \\
\hline Central & Ibicuitinga e Itatira & 19 \\
Norte & $\begin{array}{l}\text { Cariré, Cruz, Groaíras, Jericoacoara, } \\
\text { Jijoca de Jericoacoara, Lapa, Macaraú e } \\
\text { Pacujá }\end{array}$ & 17 \\
Sul & $\begin{array}{l}\text { Abaiara, Baixio, Barbalha, Barro, Cariús, } \\
\text { Cariutaba, Farias Brito, Felizardo, } \\
\text { Ipaumirim, Jati, Juazeiro do Norte, } \\
\text { Mauriti, Milagres, Nova Olinda, Palestina } \\
\text { do Cariri e Porteiras }\end{array}$ \\
& $\begin{array}{l}\text { Alto Santo, Canoa Quebrada, Eusébio, } \\
\text { Ererê, Flores, Fortaleza, Fortim, Nova }\end{array}$ \\
Leste & $\begin{array}{l}\text { Jaguaribara, Pacajús, Quixerê e São João } \\
\text { de Deus }\end{array}$ \\
& Lambedouro e Poranga \\
\hline
\end{tabular}

Fonte: Autores 
As condições de coleta (tipo de frasco, volume encontram-se detalhados no Quadro 1. a ser coletado, tipo de preservação das amostras)

Quadro 1 - Coleta e preservação das amostras para as análises.

\begin{tabular}{|c|c|c|c|}
\hline Análise & Tipo de frasco & Volume coletado & Preservação \\
\hline $\begin{array}{c}\text { Coliformes totais e } \\
\text { Escherichia coli }\end{array}$ & Polietileno & $100 \mathrm{~mL}$ & Refrigeração \\
\hline Cloreto & $\begin{array}{l}\text { Polietileno ou vidro } \\
\text { borosilicato }\end{array}$ & $250 \mathrm{~mL}$ & Não é necessário \\
\hline Amonia total & $\begin{array}{l}\text { Polietileno ou vidro } \\
\text { borosilicato }\end{array}$ & $500 \mathrm{~mL}$ & $\begin{array}{c}10 \text { gotas de ácdido } \\
\text { sulfúrico PA com } \\
\text { pH }<2\end{array}$ \\
\hline Nitrito e nitrato & $\begin{array}{l}\text { Polietileno ou vidro } \\
\text { borosilicato }\end{array}$ & $250 \mathrm{~mL}$ & $\begin{array}{c}10 \text { gotas de ácdido } \\
\text { sulfúrico } \mathrm{PA} \text { com } \\
\mathrm{pH}<2\end{array}$ \\
\hline
\end{tabular}

Fonte: Adaptado de APHA (2005)

Todas as amostras foram acondicionadas em recipientes térmicos a uma temperatura de aproximadamente $4^{\circ} \mathrm{C}$ e transportadas em um tempo máximo de 24 horas para os laboratórios da Companhia de Água e Esgoto do Ceará.

As análises microbiológicas foram feitas a partir da quantificação de coliformes totais e Escherichia coli, utilizando substrato cromogênico (Colilert®). O substrato foi adicionado ao frasco contendo 100 $\mathrm{mL}$ da amostra, homogeneizado e distribuído em cartela. Após as cartelas terem sido seladas, foram incubadas em estufa bacteriológica na temperatura de $35^{\circ} \mathrm{C} \pm 0,5$ por um período de 24 horas.

A leitura dos resultados foi considerada positiva para coliformes totais quando evidenciado a coloração amarela, provocada pela presença da enzima $\beta$-galactosidase ao metabolizar o nutriente ONPG (orto-nitrofenil-ß-D-galactopiranisídeo), após o período de incubação. Com o auxílio de uma lâmpada ultravioleta (115 volts, 6hz, 20 
AMPS) incidida sobre a cartela, foi evidenciado resultado positivo para $E$. coli, quando apresentada fluorescência, causada pela atividade da enzima ß-glucuronidase para metabolizar o substrato fluorogênico MUG (4-metilumbeliferil-ß-Dglicuronídeo) (SILVA et al., 2005). Após a contagem dos orifícios positivos nas cartelas, os resultados foram cruzados na tabela de Número Mais Provável (NMP) e o resultado expresso em NMP por $100 \mathrm{~mL}$ de amostra.

As metodologias utilizadas para as análises dos parâmetros físico-químicos e os limites máximos permitidos pela legislação brasileira estão descritas no Quadro 2.

Quadro 2 - Metodologia das análises dos parâmetros físico-químicos.

\begin{tabular}{|c|c|c|c|c|}
\hline $\begin{array}{l}\text { Parâmetro } \\
\text { Químico }\end{array}$ & $\begin{array}{l}\text { Metodologia } \\
\text { de análise }\end{array}$ & $\begin{array}{c}\text { Resolução do } \\
\text { CONAMA n }{ }^{\circ} 396 / 08\end{array}$ & Preservação & Unidade \\
\hline Cloreto & $\begin{array}{l}\text { Tritrimetria / } \\
\text { Agentometria }\end{array}$ & 250 & 250 & $\mathrm{mg}$ de $\mathrm{Cl} / \mathrm{L}$ \\
\hline Amônia & $\begin{array}{c}\text { Espectrofotometria / } \\
\text { Fenato }\end{array}$ & - & 1,5 & $\mathrm{mg}$ de $\mathrm{N}-\mathrm{NH}_{3 /} \mathrm{L}$ \\
\hline Nitrato & $\begin{array}{l}\text { Espectrofotometria / } \\
\text { Coluna redutora de } \\
\text { cádmio }\end{array}$ & 10 & 10 & $\mathrm{mg}$ de $\mathrm{N}-\mathrm{NO}_{3}^{-} / \mathrm{L}$ \\
\hline Nitrito & $\begin{array}{c}\text { Espectrofotometria / } \\
\text { Diazotização }\end{array}$ & 1 & 1 & $\mathrm{mg}$ de $\mathrm{N}-\mathrm{NO}_{2}{ }^{-/ L}$ \\
\hline
\end{tabular}

Fonte: Adaptado de APHA (2005), Brasil (2011), Brasil (2008).

Os dados dos parâmetros microbiológicos e físico-químicos foram analisados por meio de gráficos e por correlações de Pearson (r), com utilização do software Excel 2007. Na realização das correlações os dados da região Oeste devido à sua pequena amostragem (três amostras), não sendo significativos estatisticamente, foram desprezados.

Os tipos das correlações lineares foram determinadas segundo a classificação de Santos (2007). 


\section{Resultados e Discussão}

Os resultados foram agrupados por cinco macrorregiões do Estado e expressos em percentuais, observando-se que, em algumas amostras, os parâmetros analisados atingiram valores acima do permitido pela legislação.

Das 230 amostras analisadas, 92 (40\%) apresentaram crescimento de coliformes totais e em 28 (12,2\%) de Escherichia coli. Resultados semelhantes ao de Cajazeiras (2007) que em seu trabalho acerca da qualidade e o uso das águas subterrâneas da Região de Crajubar (CE), verificou que a maioria dos poços analisados (62\%) apresentaram águas contaminadas por coliformes totais e termotolerantes. Adicionalmente, Silva e Araújo (2003) e Camargo e Paulosso (2009), avaliando a qualidade bacteriológica da água subterrânea utilizada para consumo humano em áreas urbanas de Feira de Santana (BA) e em

Tabela 2 - Percentual de contaminações por coliformes totais e Escherichia coli em águas de poços por regiões do Estado do Ceará, Brasil.

\begin{tabular}{|c|c|c|c|c|}
\hline $\begin{array}{l}\text { Parâmetro } \\
\text { Químico }\end{array}$ & $\begin{array}{l}\text { Metodologia } \\
\text { de análise }\end{array}$ & $\begin{array}{c}\text { Resolução do } \\
\text { CONAMA n }{ }^{\circ} 396 / 08\end{array}$ & Preservação & Unidade \\
\hline Cloreto & $\begin{array}{l}\text { Tritrimetria / } \\
\text { Agentometria }\end{array}$ & 250 & 250 & $\mathrm{mg}$ de $\mathrm{Cl} / \mathrm{L}$ \\
\hline Amônia & $\begin{array}{c}\text { Espectrofotometria / } \\
\text { Fenato }\end{array}$ & - & 1,5 & mg de $\mathrm{N}-\mathrm{NH}_{3 /} \mathrm{L}$ \\
\hline Nitrato & $\begin{array}{l}\text { Espectrofotometria / } \\
\text { Coluna redutora de } \\
\text { cádmio }\end{array}$ & 10 & 10 & $\mathrm{mg}$ de $\mathrm{N}_{-} \mathrm{NO}_{3}^{-/ \mathrm{L}}$ \\
\hline Nitrito & $\begin{array}{l}\text { Espectrofotometria / } \\
\text { Diazotização }\end{array}$ & 1 & 1 & $\mathrm{mg}$ de $\mathrm{N}-\mathrm{NO}_{2}{ }^{-/ L}$ \\
\hline
\end{tabular}

Fonte: Autores 
Carlinda (MT), também registraram elevada contaminação destas por coliformes totais, com percentuais de $90,8 \%$ e $100 \%$ das amostras analisadas, respectivamente.

O percentual de contaminação microbiológica das amostras por região do Estado está demonstrado na Tabela 2.

As amostras oriundas da região Central do Estado apresentaram maior índice de contaminação microbiana (Tabela 2). Tal fato pode ser devido ao pequeno percentual de esgotamento sanitário da região Central (7,2\%), o menor do Estado.

$\mathrm{Na}$ área metropolitana de Fortaleza, localizada na região Leste do Estado, foram coletadas 10 amostras das quais 50\% apresentaram coliformes totais e $20 \%$ E. coli.

Esse elevado percentual de contaminação na zona urbana e rural é devido a vários fatores, sobretudo poços que geralmente apresentam localização inadequada (por exemplo, próximos à fossas sépticas), falta de manutenção e cuidado antes de utilizar a água para consumo humano (COLVARA; LIMA; SILVA, 2009).

Nos resultados dos parâmetros físico-químicos, a amônia apresentou níveis acima do permitido pela Portaria $n^{\circ}$ 2914/11/MS (1,5 mg/L de NH3) em apenas 3,5\% do total das amostras analisadas. Os níveis de nitratos e nitritos ultrapassaram o permitido na legislação para consumo humano em $7,8 \%$ e $0,9 \%$ do total de amostras, respectivamente. $\mathrm{O}$ nitrito, quando detectado, esteve dentro dos limites permissíveis na legislação em todas as regiões, com exceção da região Sul. Os níveis de cloreto ultrapassaram o limite máximo permissível das legislações vigentes $(250 \mathrm{mg} / \mathrm{L}$ de $\mathrm{Cl})$ para consumo humano em $1,7 \%$ das amostras, como demonstrado no gráfico 1 .

Gráfico 1 - Percentual de amostras que apresentaram os níveis dos parâmetros físico-químicos acima do limite permissível nas legislações vigentes nas regiões do Estado do Ceará, Brasil.

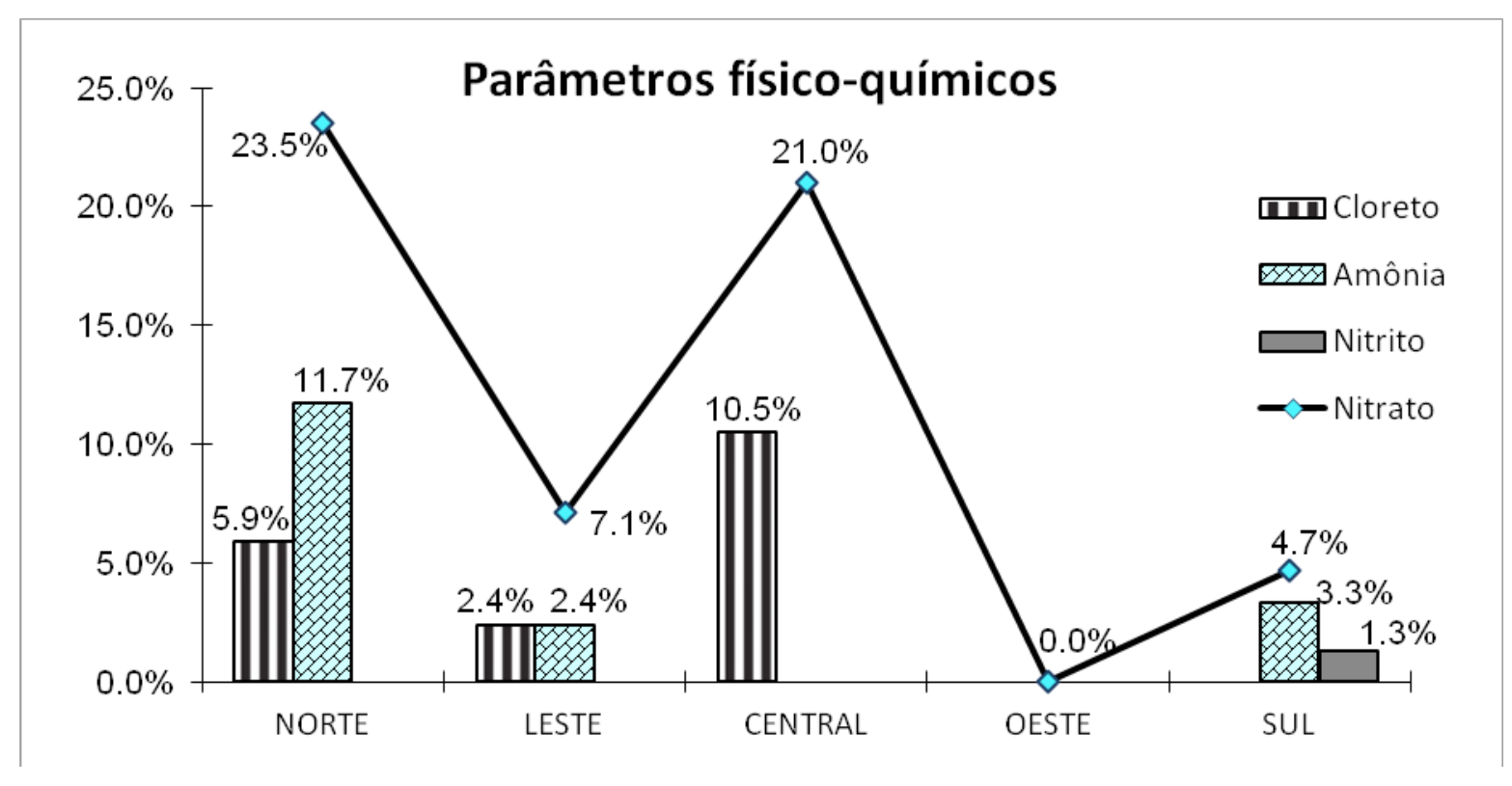

Fonte: Autores 
A região Norte apesar de possuir o maior índice de esgotamento sanitário e o menor índice de contaminação por coliformes apresentou elevados índices de amônia, nitrato e cloreto.

Diversos fatores além do nível de esgotamento podem causar alterações nas concentrações dos compostos químicos, como por exemplo, o elevado índice de nitrato que está relacionado com contaminações antigas e não recente de matéria orgânica, assim como as concentrações de cloretos, que geralmente nas águas subterrâneas são maiores do que em águas superficiais. Isso se deve ao fato que o cloreto chega fácil ao lençol freático, pois durante a sua percolação pelo solo não é absorvido (POHLING, 2009).

Os teores de amônia variaram de 0 (não detectado) a $30,45 \mathrm{mg} / \mathrm{L}$, sendo atingido este valor máximo na região Sul. Quando a água apresenta níveis de poluição elevada, com amônia acima do permitido, indica a falta de boas condições sanitárias e possível poluição por despejos domésticos (POHLING, 2009).

Resultados semelhantes foram obtidos por Franca et al. (2006), na avaliação da contaminação microbiológica e físico-química de poços tubulares em Juazeiro do Norte (CE) e afirmam que a presença de amônia nos poços em estudo pode ser atribuída tanto aos constantes lançamentos de efluentes domésticos in natura como também ao uso de fertilizantes nitrogenados na área, processos erosivos e lixiviação dos solos agrícolas.

Os teores de nitrato variaram de 0 a 99,05 mg/L e os de nitrito de 0 a 1,4 mg/L. Ambos atingiram os seus valores máximos na região Sul.

Dentre os compostos nitrogenados, o nitrato foi o identificado em maior quantidade acima dos padrões de potabilidade para consumo humano. Isso significa que nos poços analisados há mais contaminação antiga do que recente por matéria orgânica.

Isso se deve ao fato dos nitratos serem muito solúveis e não absorvidos pelo solo. Assim, contaminam as águas subterrâneas ao migrar para o lençol freático, provenientes, por exemplo, da lixiviação de fertilizantes inorgânicos e/ ou processos de decomposição e oxidação de compostos orgânicos provenientes de infiltração de esgoto de fossas sépticas e canalizações defeituosas (POHLING, 2009).

A ingestão de nitratos e nitritos por longo tempo causa diurese, danificação e hemorragia do baço, e em concentrações elevadas podem causar metemoglobinemia (cianose) em crianças, doença caracterizada pela substituição do oxigênio pelo $\mathrm{NO}_{2}^{-}$na hemoglobina do sangue (COMPANHIA AMBIENTAL DO ESTADO DE SÃO PAULO, 2009).

Os teores de cloreto variaram de 0 (não detectado) a 350,6 mg/L na região Central.

A região Sul não apresentou níveis de cloreto acima do permissível (gráfico 1), dado coerente com o estudo de Franca et al (2006) em poços de Juazeiro do Norte (CE), município localizado na região Sul do Estado, e que apresentaram em seus resultados o parâmetro cloreto dentro do permitido pela legislação $(250 \mathrm{mg} / \mathrm{L}$ de $\mathrm{Cl})$ em todas análises realizadas no referido estudo.

Quando o teor de cloreto está elevado na água e não há influências de fatores geológicos, essa contaminação pode ser proveniente de efluentes domésticos ou industriais (POHLING, 2009).

A análise estatística dos dados mostrou a presença de correlações positivas e negativas entre o índice de esgotamento sanitário e os diversos parâmetros analisados que atingiram valores acima do permitido pelas legislações vigentes, como demonstrados na Tabela 3. 
Tabela 3 - Correlações de Pearson $(r)$ entre o índice de esgotamento sanitário e os diversos parâmetros analisados nas águas de poços do Estado do Ceará, Brasil.

Parâmetros

Coliformes totais

Escherichia coli

Amônia

Nitrato

Nitrito

Cloreto

\section{Coeficiente de Pearson ( $r$ )}

\section{Tipo de correlação}

Moderada negativa

Moderada negativa

Moderada positiva

Fraca negativa

Fraca positiva

Moderada negativa

Fonte: Autores

As correlações moderada negativa e fraca indicam que quanto maior o índice de esgotamento sanitário nas diversas regiões menor o índice de contaminação por coliformes totais, E. coli, cloreto e nitrato nas águas de poços do Estado. Já as correlações moderada positiva e fraca indicam que quanto maior o índice de esgotamento sanitário nas diversas regiões maior a contaminação por amônia e nitrito. Mas isso não significa que a causa do aumento das contaminações químicas esteja relacionada diretamente ao nível de esgotamento sanitário.

Diversas variáveis podem causar o aumento de amônia, por exemplo, construções próximas de fossas sépticas incorretas; escoamento das águas pluviais de solos fertilizados em atividades agrícolas próximos aos poços o que também contribui para a presença de diversas formas de nitrogênio; assim como a chuva que transporta substâncias bem como partículas contendo nitrogênio orgânico para os corpos hídricos (COMPANHIA AMBIENTAL DO ESTADO DE SÃO PAULO, 2009).

\section{Conclusão}

Conforme a Portaria 2914/11/MS, parte das águas dos poços analisados localizados no estado do Ceará, apresentam-se impróprios para consumo humano do ponto de vista bacteriológico e físicoquímico. Uma vez que foi evidenciado elevado nível de contaminação bacteriana e cerca de $10 \%$ das amostras apresentaram os parâmetros físico-químicos fora dos padrões de potabilidade, indicando contaminação por matéria orgânica.

A qualidade microbiológica da água subterrânea do estado do Ceará está diretamente relacionada ao índice de esgotamento sanitário, onde as regiões que possuíam menor índice de esgotamento apresentaram maior taxa de contaminação.

Considerando que as águas provenientes de poços são a única fonte de abastecimento para a população de algumas regiões do Estado, a elevação do nível de esgotamento sanitário é fundamental na prevenção da transmissão de doenças de veiculação hídrica e, por conseguinte na garantia da potabilidade das águas subterrâneas. 


\section{Agradecimentos}

As autoras agradecem a Companhia de Água e Esgoto do Ceará, por proporcionar a realização desse estudo.

\section{Referências}

A.P.H.A. Standard methods for the examination of water and wastwater. 21. ed. Washington: Apha/wef/awwa, 2005.

BARRELL, R.;BENTON, C.; BOYD, P.CARTWRIGHT, R.; CHADA, C.; COLBOURNE, J.; COLE, S.; COLLEY, A.; DRURY, D.; GODFREE, A.; HUNTER, P.; LEE, J.; MACHRAY, P.; NICHOLS, G.; SARTORY, D.; SELLWOOD, J.; WATKINS, J. The microbiology of drinking water: water quality and public health. Methods for the Examination of Waters and Associated Materials. Environment Agency, 2002. Part 1.

BRASIL. Manual de saneamento. 3. ed. Brasília: Fundação Nacional de Saúde, 2007.

. Portaria $n^{\circ} 2914$ de 12 de dezembro de 2011. Brasília: Ministério da Saúde, 2011.

Resolução $n^{\circ} 396$ de 3 de abril de 2008. Brasília: Conselho Nacional do Meio Ambiente, 2008.

CAJAZEIRAS, C. C. A. Qualidade e uso das águas subterrâneas e a relação com doenças de veiculação hídrica, Região de Crajubar/CE. 2007. 143 f. Dissertação (Mestrado em Geologia) - Universidade Federal Do Ceará, Fortaleza.

CAMARGO, M. F.; PAUlosso, L. V. Avaliação qualitativa da contaminação microbiológica das águas de poços no município de Carlinda - MT. Semina: Ciências Biológicas e da Saúde, Londrina, v. 30, n. 1, p. 77-82, jan./jun. 2009.

CEARÁ. Instituto de Pesquisa e Estratégia Econômica do Ceará. Ceará em números 2010. Fortaleza, 2010. Disponível em: <http://www2.ipece.ce.gov.br/ publicacoes/ceara_em_numeros/2010/infra/saneamento. htm>. Acesso em: 12 out. 2011.

CELLIGOI, A. Considerações sobre análises químicas de águas subterrâneas. Geografia, Londrina, v. 8, n. 1, p. 91-97, 1999.

COLVARA, J. G.; LIMA, A. S.; SILVA, W. P. Avaliação da contaminação de água subterrânea em poços artesianos no sul do Rio Grande do Sul. Brazilian Journal of Food
Technology, Campinas, II SSA, 2009.

COMPANHIA AMBIENTAL DO ESTADO DE SÃO PAULO. Qualidade das águas interiores do estado de São Paulo. São Paulo: CETESB, 2009.

COMPANHIA DE ÁGUA E ESGOTO DO CEARÁ CAGECE. Índice de abastecimento público. Fortaleza. 2012. (Mimiografados).

Índice de cobertura de esgoto. Fortaleza. 2011. (Mimiografados).

ECKHARDT, R. R.; DIEDRICH, V. L., FERREIRA, E. R.; STROHSCHOEN, E.; DEMAMAN, L. C. Mapeamento e avaliação da potabilidade subterrânea do município de Lajeado, RS, Brasil. Ambiente e Água - An Interdisciplinary Journal of Applied Science, São Paulo, v. 4, n. 1, p. 58-80, 2008.

FRANCA, R. M.; FRISCHKORN, H.; SANTOS, M. R. P.; MENDONÇA, L. A. R.; BESERRA, M. C. Contaminação de poços tubulares em Juazeiro do Norte - CE. Revista Engenharia Sanitária, Rio de Janeiro, v. 11, n. 1, p. 92-102, 2006.

POHLING, R. Reações químicas na análise de água. Fortaleza: Arte Visual, 2009.

SANTOS, C. Estatística descritiva: manual de autoaprendizagem. Lisboa: Sílabo, 2007.

SILVA, F. J. A; ARAÚJO, A. L.; SOUZA, R. O. Águas subterrâneas no Ceará - poços instalados e salinidade. Revista Tecnologia, Fortaleza, v. 28, n. 2, p. 136-159, 2007.

SILVA, N.; JUNQUEIRA, V. C. A.; SILVEIRA, N. F. A. Manual de métodos de análise microbiológica da água. São Paulo: Varela, 2005.

SILVA, R. C. A.; ARAÚJO, T. M. Qualidade da água do manancial subterrâneo em áreas urbanas de Feira de Santana (BA). Ciência \& Saúde Coletiva, Rio de Janeiro, v. 8, n. 4, p. 1019-1028, 2003.

ZOBY, J. L. G. Panorama da qualidade das águas subterrâneas no Brasil. Revista Águas Subterrâneas, Natal, Supl. XV Congresso Brasileiro de Águas Subterrâneas, 2008.
Recebido em: 7 de dezembro de 2011 Aceito em: 3 de agosto de 2012 